University of Nebraska - Lincoln

DigitalCommons@University of Nebraska - Lincoln

Faculty Publications of the Center on Children, Families, and the Law

Children, Families, and the Law, Center on

2009

Protecting Well-Being While Pursuing Justice

Barbara Sturgis

University of Nebraska - Lincoln, bsturgis@ccfl.unl.edu

Follow this and additional works at: https://digitalcommons.unl.edu/ccflfacpub

Part of the Family Law Commons

Sturgis, Barbara, "Protecting Well-Being While Pursuing Justice" (2009). Faculty Publications of the Center on Children, Families, and the Law. 1.

https://digitalcommons.unl.edu/ccflfacpub/1

This Article is brought to you for free and open access by the Children, Families, and the Law, Center on at DigitalCommons@University of Nebraska - Lincoln. It has been accepted for inclusion in Faculty Publications of the Center on Children, Families, and the Law by an authorized administrator of DigitalCommons@University of Nebraska - Lincoln. 
Published (as Chapter 4) in Robert F. Schopp, Richard L. Wiener, Brian H. Bornstein, and Steven L. Willborn. (eds.), Mental Disorder and Criminal Law: Responsibility, Punishment and Competence (NY: Springer, 2009), pp. 103-115; doi 10.1007/978-0-387-84845-7_5, Copyright (C) 2009 Springer Science+Business Media, LLC. Used by permission.

\author{
CHAPTER 4
}

\title{
Protecting Well-Being While Pursuing Justice
}

\author{
Barbara J. Sturgis \\ Center for Children, Families, and the Law \\ University of Nebraska-Lincoln, Lincoln, Nebraska, USA \\ email: bsturgis@ccfl.unl.edu
}

The second and third chapters in this section draw attention to circumstances in which concerns regarding the ability of the criminal justice process to achieve just outcomes intersect with concerns regarding the potential effects of that process on the psychological well-being of various participants. These chapters by Bruce Winick, Jodi Quas, and Bradley McAuliff can reasonably be understood as complimentary in the following sense. Winick's chapter endorses a substantive legal standard and a proposed procedure for applying that standard that raises a series of questions regarding the manner in which that procedure, and the participants in that procedure, will be able to fulfill its goals. The chapter by Quas and Mc Auliff emphasizes the extensive body of empirical research addressing the effects of the criminal justice process on participating children in an attempt to promote the development of processes that will protect the well-being of those children while promoting just outcomes.

\subsection{Serious Mental Illness and Capital Punishment}

In his chapter on determining when severe mental illness should disqualify a defendant from capital punishment, Winick writes that those with severe mental illness (SMI) at the time of the offense should be afforded the same categorical preclusion from capital punishment as those with mental retardation (Atkins v. Virginia, 2002) and as juveniles (Roper v. Simmons, 2005). Both those with mental retardation and juveniles were found to be categorically less culpable and therefore less appropriate for capital punishment. He endorses the approach favored by the American Bar Association (ABA), American Psychological Association (APA), American Psychiatric Association (APA), and National Alliance on Mental Illness (NAMI), that 
there should be an exemption from capital punishment only for those with SMI who suffer significant impairment of their capacity to: (1) appreciate the nature, consequences, or wrongfulness of their conduct; (2) exercise rational judgment in relation to their conduct; or (3) conform their conduct to the requirements of law (Winick, 2009, this volume, p. 45) He outlines a number of procedural changes that could occur if such a categorical bar were in place, and he maintains that these procedural changes would positively impact not only the defendant, but also possibly the family of the victim and various other actors in the legal system.

For the purposes of this discussion, assume that there is a subset of offenders with SMI who do not qualify as not guilty by reason of insanity (NGRI), who manifest the above impairments, who are arguably less culpable than unimpaired offenders, and who probably should not face the death penalty. The question becomes how to determine who these people are, and what procedures should apply to them. Throughout the chapter, Winick relies heavily on laws and cases involving mental retardation, making the case that what applies to those with mental retardation applies to those with SMI who have the requisite "impaired capacities." While many of those with mental retardation and SMI share some similarities, there are many important differences between these two diagnostic categories. Both mental retardation and SMI cause significant impairment in individuals' functioning. The description of "impaired capacities" outlined above could certainly apply to those with mental retardation and some of those with SMI. However, there are crucial differences between these two categories of psychological impairment that raise important questions regarding the reliability of retrospective assessment of SMI in a relatively limited pretrial hearing.

First, mental retardation, at its various levels, is a specific diagnosis whereas SMI is not. Mental retardation has a specific description and agreed-upon criteria within the lexicon of mental disorders (DSM-IV, 1994). Although the precise measure of mental retardation that would constitute a barrier to capital punishment may vary from jurisdiction to jurisdiction, the category and its levels are well defined and well accepted within the mental health community. Under Winick's proposal, SMI would become a legal definition that would remain undefined clinically, and therefore would be left to courts or legislatures to determine. SMI could cover a multitude of diagnostic categories and would likely vary significantly from jurisdiction to jurisdiction. Probably the most common perception of SMI would include schizophrenia and other psychotic disorders. Those diagnoses would comport with the public's perception of what mental illness is. However, those with cognitive impairments, such as dementia and delirium, could qualify as well as those with severe mood disorders. SMI could also be descriptive of those with the serious dissociative disorders (such as dissociative identity disorder) and even in some with severe personality disorders (such as borderline personality disorder). Therefore, a good deal of the DSM-IV could be captured by potential legal descriptions of SMI.

Another concern raised by the differences between mental retardation and mental illness is that, by definition, mental retardation is a global impairment of cognitive capacities. When an individual is diagnosed with mental retardation, while there may be some variation within their limitations, they have significant deficits 
in all areas of cognitive functioning. If there is a deficit only in a specific area of cognitive functioning, that would more likely be defined as a specific learning disability. Therefore, a diagnosis of mental retardation would be an accurate and consistent prediction of a person's functional impairment in virtually all situations.

On the other hand, individuals who carry diagnoses potentially covered by the descriptor SMI can be fairly functional in some, and perhaps many areas, and they can be significantly impaired in other areas. For example, an individual might experience paranoid delusions about aliens who are trying to poison him and make him ill, but he might remain competent and confident in handling his financial obligations. He then could be severely impaired in managing his diet (only green canned vegetables) and in dealing with medical professionals (the aliens in disguise who are trying to kill him). He would not necessarily be impaired in dealing with his banker and paying his bills. Should an individual be severely impaired in a manner that profoundly affects all aspects of his life, it is hard to understand why he should not be found to be NGRI.

Not only is mental retardation a specific diagnostic category within the DSMIV, it also has well-established and standardized methods of assessment. Evaluating an individual for mental retardation is a relatively straightforward procedure. It requires the standardized administration of an individual intellectual test, an assessment of adaptive functioning, and a review of the individual's developmental history. The intelligence test assesses the individual's performance on a number of standardized tasks that have been normed on a standardized population. At the level of mental retardation that would be at issue for any legal proceedings there are one or two commonly used standardized tests. Assessment of adaptive functioning, by report of the individual and those who interact with him or her, looks at practical functioning in a wide array of daily tasks. The history determines the etiology of the retardation, including early developmental history and any events that may have affected the individual's functioning and development. An assessment and diagnosis of mental retardation can be done without any knowledge of the individual's criminal activity. It would only be at the upper levels of mental retardation (mild) that an individual would likely meet the requirements of criminal responsibility. Those at lower levels of functioning would be likely to be found not guilty by reason of mental defect and also incompetent to stand trial. In a sense, measuring intellectual functioning is much more of an actuarial process, although it does involve some clinical judgment.

While there are various assessment instruments which aid in the evaluation of those with mental illness, such assessments rely much more heavily on clinical judgment than do assessments of metal retardation. There is no single standardized method of assessing SMI, since it is not a clinical diagnosis. There are no tests comparable to intelligence test in that they are conventionally accepted as determining an individual's psychological condition as SMI. Therefore the determination of SMI is much more fluid and open to interpretation. This would be especially true at the level where the individual is not NGRI but would still be under consideration for preclusion from capital punishment. Presumably, if someone is so severely impaired that it is clear to all, it is much more likely that he or she would be found NGRI. 
Along with the fact that the symptoms of SMI vary significantly within individuals and between individuals in the same diagnostic categories, many symptoms of SMI can be ameliorated by medication. In the area of schizophrenic and psychotic disorders there is a vast array of antipsychotic medications which, for many individuals afflicted with psychoses, can reduce the more florid and disturbing symptoms. While it is difficult to completely eliminate delusional thinking, it can be reduced to a significantly more controllable level. Many antipsychotic medications can also reduce or even eliminate hallucinatory experiences. Therefore, understanding an individual's functioning at any given time would have to take into account whether he or she were medicated and the impact of medication at the time of the offense. That raises the concern that a person might qualify as SMI at one point in time, and, with proper medication controlling symptoms, not qualify as SMI at some other time, while carrying the same diagnosis. Thus, establishing that an offender manifests SMI at a particular time before or after an offense does not clearly establish that he or she suffered SMI at the time of the offense. In contrast, there are no medications that can directly improve functioning in an individual with mental retardation. There may be some medications that can improve ancillary functioning, such as medications to reduce anxiety or improve focus, but there are none that can increase intellectual functioning overall. Thus, the severity of mental retardation remains consistent over time, rendering it less difficult to retrospectively establish the severity of impairment at the time of the offense.

Therefore, a psychological assessment of an individual that would be of assistance to the court to determine whether or not he or she fits one of the diagnostic categories that would likely be included in the category of SMI would necessitate a thorough understanding of the legal standard in the particular jurisdiction and of the relationship between that standard and clinical diagnoses. For example, is anyone who carries the diagnosis of schizophrenia considered SMI or just those with serious symptoms? Is the individual not SMI at some points, as when properly medicated with symptoms well controlled, but SMI at others, when off medication and experiencing more florid symptoms? Because the recommended rule emphasizes the individual's behavior "at the time of the offense," any assessment would have to take into account the individual's psychological impairment at that time.

This proposal further narrows the category to be precluded from capital punishment to those with SMI who have a significant impairment in their capacity to appreciate the nature and consequences or wrongfulness of their conduct, to exercise rational judgment in relation to their conduct, or to conform their conduct to the requirements of the law (Winick, 2009, this volume, p. 45). Therefore, any assessment relevant to the legal questions would have to take into consideration the particular conduct and understanding of the law that the person had at the time of the crime. The assessment would involve a thorough understanding of the individual's psychological impairment at the time of the crime, the details of the crime itself, and the relationship between the two. That assessment would necessitate the defendant conceding the facts of the crime and a description of his/her thinking/ belief at the time. For example, if our paranoid individual in the above example stabbed and killed the nurse who was giving him his flu shot because he believed 
she was an alien trying to kill him, he might fit the definition of SMI and "significant impairment" for the purposes of preclusion from capital punishment. However, if that same schizophrenic individual, properly medicated, stabbed the nurse because she made him wait too long in line and he was angry, he might not be sufficiently impaired to qualify as SMI for the purposes of preclusion from capital punishment. Nor would he be if he shot a teller while attempting to rob the drive up window at his bank because he wanted more money. Knowledge of the crime and the thinking/ belief at the time would not be necessary for the assessment of mental retardation, which can be done absent any knowledge of the crime itself.

For that reason, a pretrial hearing, although focusing on the defendant's mental illness, would be much more involved than one making a determination of mental retardation. It would still necessitate a thorough airing of the "gruesome facts of the crime" in order to determine the relationship between the defendant's impaired processes and the criminal conduct. The psychologist would have to know exactly what happened and what the defendant was thinking at the time to evaluate the relationship between any diagnostic category and the crime. Since the determination of both SMI and "impaired processes" are legal decisions the judge would also have to know the details of the crime to make that judgment. That raises the question of what sources for the facts of the crime would be allowed. For example, would the psychologist or judge rely only on the information provided by the defendant or would he/she get the crime scene photos? None of this is necessary in a case involving mental retardation in which the judge only needs to decide which psychological evaluation to accept.

Given the complexity of determining that an exemption from capital punishment is warranted for some individuals with SMI, Winick's proposal that such hearings be done by judges rather than juries makes sense. The judge would have to first determine whether the individual was SMI at the time of the crime and the effect of that SMI on the criminal behavior. Given the potential for fluctuation in functioning within individuals with a history of SMI, it would be quite possible that a person who appears relatively intact at the time of the hearing was quite impaired at the time of the crime. Furthermore, determination of whether the requisite "significant impairments" occurred at the time of the crime requires a nuanced analysis of what qualifies as "significant impairments," how those impairments impacted the individual's behavior, and whether they rose to the level that would preclude capital punishment. Judges have a greater understanding of the law and are "probably more due process oriented than capital juries" (Winick, 2009, this volume, p.). Judges would likely have more exposure to cases in which SMI plays a part, either for NGRI or in other exemption hearings. They would therefore have a wider experiential base with which to compare the extant case to others, as well as more experience with evaluating expert testimony. This recommendation is consistent with David Baldus' research into judicial versus jury sentencing in capital cases (Baldus, Woodworth, Grosso, \& Christ, 2002). He found support for greater consistency in judicial sentencing compared to jury sentencing (Baldus et. al., 2002, p.669). Preclusion of an individual with SMI and the requisite impairments would be potentially more complex than capital sentencing and require more legal un- 
derstanding and more sophistication with regard to mental health issues than would be found in most juries.

Winick also raises considerations with respect to Therapeutic Jurisprudence the intentional and unintentional psychological impact of the law on the well-being of the people involved (Wexler \& Schopp, 1992). His contention is that having the issue of preclusion from capital punishment decided pretrial would significantly reduce the stress on those involved in the process. It seems reasonable that if the defendant were found not eligible for capital punishment in a pretrial hearing, there would be significantly less stress for those involved in the guilt and penalty phases of the actual trial. They would not face the possibility that the defendant might eventually be put to death as a result of their decisions. He noted that there would likely be less intense scrutiny on the judge in a non-capital trial as well as less potential distress for the jury. The same could hold true for the attorneys. There is a question regarding the feelings of the family of the victim. While some may feel relief at having the death penalty off the table and therefore the potential of more timely closure, others may feel cheated out of the retribution they feel is deserved.

Although those involved in the pretrial hearing would be making decisions that could place the defendant in the position of being eligible for capital punishment, it is reasonable to expect that the stress would still be less than the stress of a capital sentencing hearing since they would be insulated from the final outcome by the guilt and penalty phases of the actual trial. The judge (or jury) would know that even if the defendant was found eligible for capital punishment, several more legal proceedings intervene prior to his or her facing death. While Winick did not mention the psychologist, it would also seem reasonable to expect that participating in a pretrial determination of eligibility for capital punishment would be less stressful than relevant evaluations further along the process, such as an evaluation of competency to face execution. Presiding at a pretrial hearing might be quite stressful for the judge, however, in that he or she may face even more intense scrutiny as the sole decision-maker regarding whether the defendant would ultimately face capital sentencing.

Throughout the paper, Winick focuses on the blessings that would occur if an individual with SMI and the requisite impairments could be precluded from capital punishment in a pretrial judicial hearing. He does not discuss the impact of such a process when the defendant is found eligible for capital punishment. All of the Therapeutic Jurisprudence advantages would vanish. The stressors on the individuals involved in a capital trial would still be present, along with the added strain of the rather complex pretrial hearing itself, almost the trial before the trial. Winick was also concerned about the "lens" through which a capitalqualified jury views the evidence in a capital trial. If the use of a pretrial hearing to determine eligibility for capital punishment were commonly understood, and the defendant were found to be eligible, jurors would potentially have another "lens" through which to view the defendant and the evidence. First, the defendant would have conceded the details of the crime for the purposes of the pretrial hearing. Would this increase the likelihood of a guilty verdict at trial? Second, a judge has decided that the defendant was sane enough to face the possibility of 
the death penalty. The jury might assume that the sanity issue has been settled and no longer needs to be considered. This might, for example, have a significant effect on a jury's willingness to consider mental illness, or even SMI, as a mitigator during the penalty phase.

Another question arises regarding how this pretrial process would work in conjunction with a potential plea of NGRI. Since the issue of NGRI is handled at trial, would the defendant have to pursue a pretrial hearing to determine if he/ she is eligible for capital punishment and then present the NGRI defense at trial, or would a pretrial determination of eligibility effectively preclude an NGRI defense, although it technically should not? Insofar as the defendant must pursue each claim in separate phases, would the pretrial process regarding SMI contaminate the accurate evaluation of the NGRI defense during the trial? Alternately, would the desire to pursue a NGRI defense lead the defendant to make a strategic decision to forgo the pretrial SMI hearing in circumstances in which it should be addressed?

It seems likely that there is a subset of defendants who, while not NGRI, are sufficiently impaired because of SMI to be less culpable and not deserving of the death penalty. The question becomes how to accurately identify these people, and what procedures should be used to ensure fairness. The process endorsed by Winick has the potential to be extremely complex and vary widely from jurisdiction to jurisdiction. For some participants in these procedures, the pretrial determination might reduce the psychological stress without undermining other important considerations, such as the accuracy of the determinations and comparative justice. The potential length and complexity of such hearings suggests, however, that they might inflict substantial stress on some participants under some circumstances. Alternatively, attempts to reduce the length or complexity of such hearings might undermine attempts to attain comparative or non-comparative justice. Thus, an attempt to design and implement such hearings in a manner that ameliorates harm to the psychological well-being of the participants will require an extended inquiry regarding a complex set of empirical and justificatory questions.

The third chapter in this section discusses a related set of empirical studies that are relevant to a different category of criminal proceedings.

\subsection{Protecting Child Victim Witnesses}

Quas and McAuliff present information on children's involvement in the criminal justice system. They emphasize both the necessity of having children in court and also the potential impact of that participation on children's well-being. They present data on the kinds of stressors that can occur when children are involved in legal procedures and the kinds of accommodations that might be made to mitigate those stressors. Some of those stressors include lack of legal knowledge, repeated interviews especially by different people whom the children do not know, testifying, facing the perpetrator in court, case length, and case outcome. Relatively non-controversial interventions that have addressed some of these stressors include providing information about the legal process to child witnesses, coordi- 
nating investigations through the use of child advocacy centers (CACs), and providing support persons. Other, more controversial changes to procedures, have included the use of videotaped testimony and testimony outside the courtroom via closed circuit television.

Quas and McAuliff refer in particular to data about child victims of sexual abuse who become witnesses since much of the research on children's involvement as witnesses in both the criminal and juvenile systems has been done with this population. They note that there are many factors common to child sexual abuse cases that are also common in other kinds of criminal cases. These include case length, repeated interviews, testifying, and case outcomes. However, there are important factors central to sexual abuse cases that may not be found in other situations where children might testify. Primary among them is that most children who testify in sexual abuse cases are the victims. Most often, they have a prior relationship with the perpetrator who uses that relationship to involve the child in sexual activity. Since children rarely disclose sexual abuse immediately (if ever) the abuse has often continued over a significant period of time (Lyon, 2007; Roesler \& Wind, 1994). Because of these factors and the sexual nature of the crime, child victim/witnesses commonly experience lasting feelings of responsibility, shame, embarrassment, and guilt (Sgroi, 1982; Roesler \& Wind, 1994). They often feel guilty for the abuse itself, for the disruption caused by the disclosure, and for the consequences to the perpetrator whom the child may care about. Also, it is not uncommon for them to risk relationships with other family members by virtue of the disclosure. Therefore, child sexual abuse cases, while likely being the most common situation in which children testify, and while providing most of the available data on the impact of legal proceedings on children, present additional stressors that may not be present in other types of cases where children might testify.

Regarding the consequences of legal involvement on children, Quas and McAuliff enumerate a number of areas that may cause stress or trauma for children. The first area they discuss is legal understanding. They note that children are limited in both general legal knowledge and also about the specifics of their case. The question becomes how this lack of knowledge impacts both children's ability to participate fully as witnesses and the level of distress that they feel. Children who are maltreated often feel partly responsible for the maltreatment and may assume that the legal involvement signifies that they are in trouble or that they are causing trouble for others. Children who are fearful that they are in trouble may disclose less information and experience more confusion and stress during the process. Because providing children with information regarding legal proceedings would not negatively impact those proceedings, it would appear to be a straightforward way to enhance children's participation and potentially reduce stress.

Children need information both about how the court system works in general and about the specifics of their case. This may reduce their level of anxiety and contribute to the perception that the process is fair (Melton et al., 1992). Research efforts might refine our understanding of the kinds of legal information that are important to children of particular age groups, the best method for delivery, and how to assess whether children truly understand the information they need. For 
example, there has been significant research in the medical field on the utility of preparing children prior to medical procedures (Cardona, 1994). Some of those studies have looked at parents providing the information and the use of videotapes of children explaining the procedures to children, which the children have found helpful in reducing their anxiety and in helping them cope with the procedure itself (Pinto \& Hollandsworth, 1989). As with adults, keeping children informed regarding the specifics of their case and why things take as long as they do is important. Children's perception of time is different from adults' sense of how long things take. It is also harder for especially young children to keep track of the passage of events. Therefore, they need more support and ongoing information to understand the status of their case.

Another potential source of stress that Quas and McAuliff review is the impact of repeated interviews on children. Certainly, at the investigative stage, there is significant concern regarding the impact of repeated interviews on children (Poole \& Lamb, 1998; Ceci \& Bruck, 1995; Olafson, 2007). This concern stems from the need for accuracy and from sensitivity to the impact of the process on children. The modifications in the investigative process that have been recommended, including minimizing unnecessary multiple interviews and the use of child advocacy centers, reflect the recognition that repeated questioning of children has the potential for affecting the quality of information as well as the child's experience (Faller, 2007). Although children report that the experience of multiple interviews is negative (Tedesco \& Schnell, 1987; Quas et al., 2005), research efforts might focus on the impact of such interviews when they have been conducted in a child friendly, developmentally appropriate manner. It can be quite a relief for children to finally talk about ongoing abuse, a burden they often bear in secret. Also, children are fairly flexible when the reasons for adult actions are explained. Thus, if repeated interviews are necessary to gather or clarify relevant information, or to prepare for court, children might be able to handle them fairly well if they are done appropriately, the reason is explained, and the children understand the process.

Quas and McAuliff note that testifying appears to be the most stressful act of legal involvement for children. Testifying is difficult for both children and adults. A major source of stress for children in the courtroom is having to face the defendant. Facing the perpetrator - in sexual abuse cases it is most likely someone with whom the child has had a trusted relationship - is what children say is the most stressful part of being in court (Goodman et al., 1992). When children don't understand the protections that are in place, they may fear that the perpetrator may be able to approach them in the courtroom. Even when children recognize that they are physically safe in the courtroom, they worry about what the perpetrator may be able to do to them outside of court, which in some cases is not unrealistic. Since most of the child victim/witnesses who have been studied have been in extended abusive relationships with the perpetrator, they often continue to feel vulnerable and anxious even when their physical safety is assured. Aside from fear (realistic and unrealistic), child victim/witnesses often feel guilty about testifying against a parent, relative, or friend. Also, they are embarrassed about having to 
talk about sexual matters in open court. Again, many of these factors are unique to the population most often studied.

Children are anxious about facing the perpetrator, even in therapeutic settings. However, particularly in sexual abuse cases, facing the perpetrator and expressing their distress about what happened to them is an important part of the healing process for victims. This process acknowledges the reality of the abuse and who is responsible for it. It is especially important that the non-offending parent, usually the mother, acknowledges the reality of the abuse, condemns it, and is supportive of the victim. When the perpetrator takes responsibility for his behavior and, hopefully, apologizes, it is even more therapeutic for the victim. That raises the question of whether or how testifying in court can attain some of these same therapeutic gains. It is possible that testifying in open court could be a way for the child to openly declare the reality of the experiences that they have had. It is also a way for adults to listen to and take seriously what the child has to say, with a very formalized procedure. Grown-ups are listening carefully to the child and asking questions to understand better. Even cross examination, which can be confusing for both adults and children, is an acknowledgment of what the child has said. If children can be taught how to manage difficult cross examination, that further validates what they have to say. Research that informs our ability to create procedures that support the child's ability to respond adaptively to cross examination would enhance the children's well-being and their ability to contribute to an effective process of adjudication.

A related issue that Quas and McAuliff note is the manner and question type used in cross examination. A major focus of training for those who investigate child abuse and child sexual abuse is how to talk to children in a developmentally appropriate, non-leading manner (Poole \& Lamb, 1998). Cross-examination, if anything, is often the opposite. Questions can be confusing and highly suggestive. The language is often inappropriate for the child's age and experience. As they point out, these kinds of questions are often difficult for adults and beyond the ability of children to comprehend. Accommodations are already made for individuals who are deaf and for those who do not speak English. It might be worth studying what kinds of courtroom linguistic accommodations would promote the ability of children to testify as accurately and completely as possible. Presumably, such accommodations would also reduce confusion and therefore distress for those children. Professionals who provide expert testimony often pursue extensive training in preparing to testify effectively. Perhaps some analogous form of training would assist many children in increasing their level of accuracy and in reducing the amount of distress they experience.

One of the factors that impacts how well children react to testifying appears to be maternal support. Children who do not receive maternal support during legal proceedings function significantly more poorly over time (Goodman et al., 1992). Similarly, children who receive maternal support are likely to disclose sexual abuse earlier and experience less distress (Elliott \& Briere, 1994; London, Bruck, Ceci, \& Shuman, 2005; Olafson \& Lederman, 2006; Shaw, Lewis, Loeb, Rosado, \& Rodriguez, 2001). Previous research has found that children's perceptions of the legal process may very well be mediated by the perceptions of their caretakers (Good- 
man et al., 1992). Thus, it is possible that some of the anxiety that children feel about testifying and their negative feelings about the process may be a reflection of what they are hearing from their parents or sensing about their parents' emotions. Although much consideration has focused on what to do for children directly, both during the investigative and testimony phase, it appears that a significant mitigator of distress throughout the legal process is the presence of a supportive adult, most usually the mother in child sexual abuse cases. Therefore, another important avenue for supporting children in legal settings should focus on the role of the parent or adult support person and on identifying the kinds of interventions that would enhance their effectiveness with the children. If parents are less anxious, if they thoroughly understand the legal process, and if they feel the process is fair, their attitudes will likely influence their children's perceptions. This would be particularly true for the youngest and therefore most vulnerable children.

Possible ways of preventing children from experiencing the stress of testifying in open court include the use of videotaped testimony or closed circuit television. Quas and McAuliff outline the research in this area and note that these accommodations, while possibly reducing the stress on children, remain highly controversial because they require significant modification of trial court proceedings and may impinge upon the right of the defendant to cross-examine the child. These rarely used modifications to courtroom procedures, while reducing immediate stress, may have longer term unintended consequences for children. As noted, children most often testify because they have been abused, most frequently in the form of sexual abuse. However, with any abuse, children typically feel guilty about what has happened to them. The abuse is usually kept secret which, aggravates its psychological effect on the child. The use of videotaped testimony which keeps the child out of court may eliminate the stress of the child having to appear in court, but may perpetuate the sense that what has happened to the child should be kept secret because it is shameful. The same concerns are relevant to the use of closed-circuit television to allow children to testify outside the open courtroom. It may reinforce the notion that children need to hide from both the perpetrator and the embarrassment of what has happened to them. Being able to testify in open court about what has happened to them may have the potential to be therapeutic for some children. In the studies from other countries that compared closed-circuit testimony with open court testimony, were the children who testified in open court properly prepared to do so? The degree and quality of preparation might substantially influence the relative stressfulness of testifying via closed-circuit television and of testifying in open court.

In their conclusion, Quas and McAuliff reference therapeutic jurisprudence and recognize that law is a social force that can bring about therapeutic or antitherapeutic outcomes for those involved. They note that we cannot eliminate all stress for children who participate in legal procedures. We should question, however, whether we should want to eliminate all stress. It is important in reflecting upon this question and this literature that we distinguish between stress and trauma. Often when we look at information on the impact of court procedures on children, stress and trauma seem to be used interchangeably. The mere fact that something creates anxiety or stress does not mean that it will cause trauma. 
Trauma "is an emotional wound or shock that creates substantial, lasting damage to the psychological development of a person, ..." (American Heritage, 2000). When individuals face stressful situations and are able master them, such experiences have the potential to increase coping skills and a sense of self-efficacy (Bandura, 1986). Therefore, we should ask whether the stress of legal procedures, specifically testifying, is necessarily bad for children if they have the proper tools with which to manage that stress? We should certainly modify those aspects of legal proceedings that cause unnecessary stress, such as unnecessary repeat interviews, lack of knowledge, and other sources of such unnecessary stress. However, children might be best served by teaching them how to cope with the distress and difficulties involved in dealing with the court process. Children also might be well served by educating their caretakers about how to cope with their child's stress and with their own. Therefore, assisting the children and their caretakers in managing the stress of testifying may substantially influence the longterm effects of participation in the legal process.

\section{References}

Atkins v. Virginia, 536 U.S. 304 (2002).

American Heritage Dictionary of the English Language, 4th Edition. (2000). Boston: Houghton Mifflin Company.

Baldus, D. C., Woodworth, G., Grosso, C. M., \& Christ, A. M. (2002). Arbitrariness and discrimination in the administration of the death penalty: A legal and empirical analysis of the Nebraska experience (1973-1999). Nebraska Law Review, 81, 486-756.

Bandura, A. (1986). Social foundations of thought and action. New Jersey: Prentice-Hall.

Cardona, L. (1994). Behavioral approaches to pain and anxiety in the pediatric patient. Child and Adolescent Psychiatric Clinics of North America, 3(3), 449-464.

Ceci, S. J., \& Bruck, M. (1995). Jeopardy in the courtroom: A scientific analysis of children's testimony. Washington, DC: American Psychological Association.

Diagnostic and statistical manual of mental disorders (DSM-IV). (1994). Washington, D.C.: American Psychiatric Association.

Elliott, D. M., \& Briere, J. (1994). Forensic sexual abuse evaluations of older children: Disclosures and symptomatology. Behavioral Sciences and the Law, 12, 261-277.

Faller, K. C. (2007). Interviewing children about sexual abuse: Controversies and best practice. New York: Oxford University Press.

Goodman, G. S., Taub, E. P., Jones, D. P. H., England, P., Port, L. K., Rudy, L., \& Prado, L. (1992). Testifying in criminal court. Monographs of the Society for Research in Child Development, 57 (5, Serial No. 229).

London, K., Bruck, M., Ceci, S. J., \& Shuman, D. W. (2005). Disclosure of child sexual abuse: what does the research tell us about the ways that children tell? Psychology, Public Policy, and Law, 11, 194-226.

Lyon, T. D. (2007). False denials: Overcoming methodological biases in abuse disclosure research. In M. E. Pipe, M. E. Lamb, Y. Orbach, \& A. C. Cederborg (Eds.), Child sexual abuse: Disclosure, delay and denial (pp. 41-62). Mahwah, New Jersey: Lawrence Erlbaum Associates. 
Melton, G. B., Limber, S., Jacobs, J. E., Oberlander, L. B., Berliner, L., \& Yamamoto, M. (1992). Preparing sexually abused children for testimony: Children's perceptions of the legal process (Final report to the National Center on Child Abuse and Neglect, Grant No 90CA-1274). Lincoln: University of Nebraska-Lincoln, Center on Children, Families, and the Law.

Olafson, E. (2007). Children's memory and suggestibility. In K. C. Faller, Interviewing children about sexual abuse: Controversies and best practice (pp. 10-34). New York: Oxford University Press.

Olafson, E., \& Lederman, C. (2006). The state of the debate about children's disclosure patterns in child sexual abuse cases. Juvenile and Family Court Journal, 57(1), 27-39.

Pinto, R. P., \& Hollandsworth, J. G. (1989). Using videotape modeling to prepare children psychologically for surgery: Influence of parents and costs versus benefits of providing preparation services. Health Psychology, 8(1), 79-95.

Poole, D. A., \& Lamb, M. E. (1998). Investigative interviews of children: A guide for helping professionals. Washington, DC: American Psychological Association.

Quas, J. A., \& McAuliff, B. D. (2009). Accommodating child witnesses in the criminal jsutice system: implications for death penalty cases. Chapter 3 in Robert F. Schopp, Richard L. Wiener, Brian H. Bornstein, and Steven L. Willborn. (eds.), Mental Disorder and Criminal Law: Responsibility, Punishment and Competence. New York: Springer (this volume).

Quas, J. A., Goodman, G. S, Ghetti, S., Alexander, K. W., Edelstein, R., Redlich, A. D., Cordon, I., \& Jones, D. P. H. (2005). Childhood sexual assault victims: Long-term outcomes after testifying in criminal court. Monographs of the Society for Research in Child Development, 70 (2, Serial No. 280).

Roesler, T. A., \& Wind, T. W. (1994). Telling the secret: Adult women describe their disclosures of incest. Journal of Interpersonal Violence, 9(3), 327-338.

Roper v. Simmons, 543 U.S. 551 (2005).

Sgroi, S. (1982). The handbook of clinical intervention in child sexual abuse. Lexington, Massachusetts: D.C. Heath and Company.

Shaw, J. A., Lewis, J. E., Loeb, A., Rosado, J., \& Rodriguez, R. A. (2001). A comparison of Hispanic and African-American sexually abused girls and their families. Child Abuse $\mathcal{E}$ Neglect, 25, 1363-1379.

Tedesco, J. F., \& Schnell, S. V. (1987). Children's reaction to sexual abuse investigation and litigation. Child Abuse \& Neglect, 11, 267-272.

Wexler, D. B., \& Schopp, R. F. (1992). Therapeutic jurisprudence: A new approach to Mental Health Law. In D. K. Kagehiro \& W. S. Laufer (Eds.), Handbook of psychology and law (pp. 361-379). New York: Springer-Verlag Press.

Winick, B. (2009). Determining when severe mental illness should disqualify a defendant from capitol punishment. Chapter 2 in Robert F. Schopp, Richard L. Wiener, Brian H. Bornstein, and Steven L. Willborn. (eds.), Mental Disorder and Criminal Law: Responsibility, Punishment and Competence. New York: Springer (this volume). 